\title{
Effect of Ti-lon Implantation on The Mechanical and Corrosion Properties of The Fecrni Super Alloy
}

\author{
Ari Handayani1, Bernadus Bandriyana1, Tjipto Sujitno², Arbi Dimyati \\ ${ }^{1}$ Center for Science and Technology of Advanced Materials, BATAN, Indonesia \\ ${ }^{2}$ Center for Accelerator Science and Technology, BATAN, Indonesia
}

\section{Abstract}

Ion implantation is widely used for surface treatment to modify the near surface properties of materials especially semiconductors without changing their bulk properties. In this work an investigation on the effect of implantation by Ti-ion on the mechanical properties and the wet corrosion of the high $\mathrm{Cr}$ and $\mathrm{Ni}$ content FeCrNi alloy was performed. Because of its superior properties this alloy is also well known as super alloy and often used as structure material in nuclear reactors. The alloy containing of $55.98 \mathrm{wt} . \% \mathrm{Fe}, 23.46 \mathrm{wt} . \% \mathrm{Cr}, 18.23 \mathrm{wt} . \% \mathrm{Ni}$ and small amount of other
Corresponding Author: Ari Handayani; email: arihandayani@batan.go.id

Received: 29 July 2016 Accepted: 21 August 2016 Published: 21 September 2016

\section{Publishing services}

(c) Ari Handayani et al. This article is distributed under the terms of the Creative commons Attribution License, which permits unrestricted use and redistribution provided that the original author and source are credited.

Selection and Peer-review under the responsibility of the ICONETS Conference Committee. provided by Knowledge E metal elements, was fabricated in BATAN Bandung. The alloy sample was subjected to Ti-ion implantation in anion generator with theoretical doses varied between $0.89 \times 10^{16}, 2.68 \times 10^{16}, 3.58 \times 10^{16}$ and $10.75 \times 10^{16} \mathrm{ion} / \mathrm{cm}^{2}$ respectivelly. The hardness measurement was conducted with Vickers method and the corrosion resistance test was carried out in the borax acid $\left(\mathrm{HBO}_{3}\right)$ environment. The microstructure of the material after implantation was characterized and analyzed by means of the Scanning Electron Microscopy (SEM) equipped with the Energy Dispersive X-Ray Detector (EDX) while the surface crystal structure was idenfied using X-Ray Diffraction (XRD). The result showed that the Ti implantation improved the surface hardness when the dose was higher than $3.58 \times 10^{16}$ ion $/ \mathrm{cm}^{2}$, while the corrosion resistance increased abruptly at all ion doses. However, no microstructure change could be observed on the cross section. A thin layer which is indicated by BSE image contrast was observed in the top most surface. Analysis on the EDS spectrum revealed that the layer could be considered to be the titanium oxide elucidating the increasing of hardness and exceptionally higher resistance to wet corrosion.

Keywords: Ti-Implantation, FeCrNi super alloy, hardness, corrosion resistance, SEM, EDX, XRD.

\section{Introduction}

Ion implantation is applied for modification of material surfaces where no change of final dimension allowed. But historically ion implantation has been especially used for doping semiconductor materials because it allows reaching a high impurity filling factor in an irradiated matrix beyond the equilibrium limit of impurity solubility 
compared to conventional technique such as high temperature diffusion technique [1]. It can also provides controllable synthesis of metal or semiconductor nanoparticles (NPs) at various depths under the substrate surface.

Today the mechanism of ion implantation is well establish as indicated by a large number of publication $[2,3]$. However, most of them used light atoms as implanted ions. It is widely accepted by many researchers, that due to high acceleration energy the ion implantation causes both impurity incorporation and material defect or amorphization. These could lead to changing of chemical and physical properties of material in the near surface. In most cases defects can be healed by annealing at high temperature [4]. Didyk et al. used deuterium ion implantation by low energy ion irradiation beam line technique to create high hydrogen concentration in the subsurface area of some pure metals ( $\mathrm{Cu}, \mathrm{Zr}, \mathrm{Pd}, \mathrm{Ti}, \mathrm{V}$ ) and $\mathrm{Pd}$-alloys [5]. They observed nanosized defects on all samples as revealed by small angle $\mathrm{X}$-ray scattering. Nitrogen or other ions can be implanted into a tool steel target. The structural change caused by the implantation produces a surface compression in the steel, which prevents crack propagation and thus makes the material more resistant to fracture. The chemical change can also make the tool more resistant to corrosion. In some applications, for example prosthetic devices such as artificial joints, it is desired to have surfaces very resistant to both chemical corrosion and wear due to friction. Ion implantation is used in such cases to engineer the surfaces of such devices for more reliable performance. As in the case of tool steels, the surface modification caused by ion implantation includes both a surface compression which prevents crack propagation and an alloying of the surface to make it more chemically resistant to corrosion.

Little publication about the implantation of heavy atoms such as Ti on steel or high alloyed steel. [6] studied surface modification of austenitic stainless steel by titanium ion implantation using RBS and GDOES at ion dose $2.3-5.4 \times 10^{16}$ ion $/ \mathrm{cm}^{2}$ and ion energy between 60 and $90 \mathrm{keV}$. The result revealed increasing of surface hardness and maximum Ti concentration in $30-50 \mathrm{~nm}$ depth at highest energy. All of the samples show increasing wear resistance due to formation of oxide layer on top surface. No information, however, about the microstructure change of the implanted sample was reported. Improved corrosion resistance in acid solution has been observed by Feng et al. in their investigation on the $316 \mathrm{~L}$ stainless steel implanted by $\mathrm{Ti}$ ion at dose $2 \times 10^{17} \mathrm{ion} / \mathrm{cm}^{2}$ and accelerating energy up to $80 \mathrm{kV}$ [7]. XPS measurement showed projected range $\mathrm{R}_{\mathrm{p}}$ of $\mathrm{Ti}$ atom at the distance of $12 \mathrm{~nm}$ beneath the surface. But SEM image on top view revealed the severe surface roughing due to mechanical destruction of ion bombardement especially at high ion energy. Gaguk et al. reported about the implantation of stainless steel AISI 410 with TiN [8]. The study observed higher corrosion resistance in acidic solution. It showed maximum hardness at dose $10.75 \times 10^{16}$ ion $/ \mathrm{cm}^{2}$ but no information about the Ti composition in the sample and the surface microstructure change after implantation.

In this work, ion implantation was performed on FeCrNi alloy by Ti-ion which aimed to modify surface properties of the alloy enhancing the corrosion behaviour in extrem environment especially in nuclear facilities. The stress of the work is put on the observation of structural changes and their characterization. Super alloys based on FeCrNi exhibit superior mechanical and oxidation properties at high temperature suitable for application in many field. However for application as structural material in 
nuclear facilities the alloy must full fill additional requirement namely its resistance under corrosive environment.

\section{Experimentals}

The materials used in this work were $\mathrm{Cr}$ and $\mathrm{Ni}$ rich super alloy developed and manufactured at the center for Science and Technology of Advanced Materials PSTBM-BATAN in framework of the national program on experimental power reactor research as reported previously [9]. The chemical composition of the alloy was examined using optical emission spectroscopy (OES) and is shown in Table 1.

\begin{tabular}{|l|l|l|l|l|l|l|l|l|l|l|l|}
\hline element & $\mathrm{Fe}$ & $\mathrm{Ni}$ & $\mathrm{Cr}$ & $\mathrm{Si}$ & $\mathrm{Mn}$ & $\mathrm{C}$ & $\mathrm{Ti}$ & $\mathrm{V}$ & $\mathrm{Sn}$ & $\mathrm{P}$ \\
\hline weight \% & 55.98 & 18.32 & 23.46 & 2.55 & 0.075 & 0.073 & 0.003 & 0.037 & 0.006 & 0.002 \\
\hline
\end{tabular}

TABLE 1: Chemical composition of used materials.

Prior to ion implantation the materials are cut to $10 \times 10 \times 5 \mathrm{~mm}$ of diameter using high precision disc cuter and subjected to grinding using sand papers down to 2000 roughness grade and fine polishing with $0,1 \mathrm{um}$ diamond paste. The ion implantation is performed with ion energi $100 \mathrm{keV}$ at current $20 \mu \mathrm{A}$ for $60,90,120$ and 180 minutes. Ion dosis applied were calculated using the formula $D=/ \mathrm{t} /$ e $A, I=$ current, $t$ = exposure time, $e=$ electron charge $\left(1,602 \times 10^{-19}\right.$ coulomb $)$ and $A=$ implant area, giving dosis $0,89 \times 10^{16} \mathrm{ion} / \mathrm{cm}^{2}, 2,68 \times 10^{16} \mathrm{ion} / \mathrm{cm}^{2}, 3,58 \times 10^{16} \mathrm{ion} / \mathrm{cm}^{2}$ and $10.75 \times 10^{16}$ respectively.

After implantation the samples were transfered for hardness measurement and wet corrosion test. The Hardness was examined using micro hardness tester Shimadzu each on at least 3 posisition. Wet corrosion is performed using EG \& G Potensiostat/ Galvanostat with the parameters; Area $=1 \mathrm{~cm}^{2}$, Eq Weight $=23.38 \mathrm{~g}$ and density $=7.98 \mathrm{gm} / \mathrm{cm}^{3}$. A sample coin of $1 \mathrm{~cm}$ of diamater and $2 \mathrm{~mm}$ of thickness was cut from bulk material in order to fit in the sample holder. Microstructural and chemical composition of the implanted area were examined using SEM JEOL JSM6510LA equipped with energy dispersive X-ray detector (EDX). SEM investigation is performed at constant electron ecceleration voltage $20 \mathrm{keV}$ and standard work distance $10 \mathrm{~mm}$ fitted to EDX requirement. The imaging detector used backscattered electrons to capture phase sensitive BSE image helpfull in distinguishing between two or more in composition different thin layer. Short but basic explanation of SEM analysis was reported elsewhere [10]. For X-ray diffraction (XRD) measurement XD610, Shimadzu was used to study the crystallographic structures of the samples. Parameter used were target $\mathrm{Cu}-\mathrm{K} \alpha$, low angle : 20 , high angle : 100, preset time $: 1.0 \mathrm{~s}$ dan step width : $0.05 \mathrm{deg} / \mathrm{step}$. Phase identification was approximated with help of RIETAN method.

\section{Result and Discussion}

Figure 1 shows the result of hardness measurement. The hardness is nearly constant over the applied ion doses which is about $140 \mathrm{HV} 25$. However it slightly increases after implantation at dose higher than $3.58 \times 10^{16} \mathrm{ion} / \mathrm{cm}^{2}$ and becomes 180 $\mathrm{HV}_{25}$ at dose $10.75 \times 10^{16} \mathrm{ion} / \mathrm{cm}^{2}$. This can be concluded that at acceleration energy of 
$100 \mathrm{keV}$ the implantation by Ti-ion can affect the mechanical property of high $\mathrm{Cr}$ and $\mathrm{Ni}$ content FeCrNi alloy only if high dosis applied. The cause of this behaviour is unclear. Possible explanations were twofold, firstly that even at the energy of 100 $\mathrm{keV}$ the implantation for short time were to low for Ti-ion to break the potential barrier for a penetration into the crystall lattice due the density and composition of the alloy. The Ti atoms then form very thin layer, may be consisting of some atom monolayer, which under measurement micro hardness test condition can not detectable. The total hardness were determined by the hardness of material substrate. Secondly, the increase of the hardness at high dose, therefore, simply might be related with the Ti enrichment under the sample surface which occurs when the availability of the Ti high enough due to long implantation time. This stand in fully aggreement with the measurement of [6], who confirmed this correlation. However the result of earlier study of Jatisukamto et al. about TiN implantation on AISI 410 showed continuous increasing of hardness at lower dosis which decreased at high dosis [8]. This defference might be caused by the role of much smaller Nitrogen atoms.

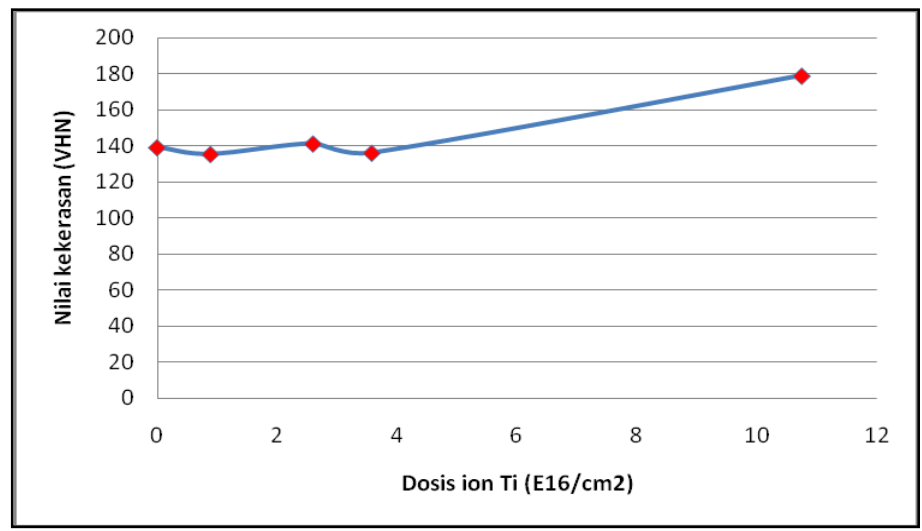

Figure 1: Hardness as a function of ion dosis.

Figure 2 shows the SEM image of the sample cross section after implantation at highest dose $10.75 \times 10^{16}$ ion $/ \mathrm{cm}^{2}$ and its corresponding EDX spectrum taken from the near surface area as directed by arrow. The EDX spectrum indicates the existent of Tirich layer on the alloy surface with exceptionaly high carbon content. Total concentration of $\mathrm{Ti}$ is $0.06 \%$. This value is near the detection limit of EDX measurement. From the SEM cross section it is hard to get a solid statement about the thickness of this layer because it is perfectly superimposed by the bright contrast due to the edge effect. Based on the element analysis of the EDX spectrum the authors assume the $\mathrm{Ti}$ rich layer might consist of $\mathrm{Ti}$ atom clusters or tiny $\mathrm{Ti}$ carbides/oxides. This layer might contribute to the slight increase of hardness on the sample surface implanted at high dose as described above. The temperature during implantation was to low to produce sufficient potential different for running a diffusion of Ti atoms toward alloy matrix. On top of the sample the EDX measurement can not detect the Ti atoms, this is might be due to the vertical detection limit of EDX much lower than lateral one. It is obvious that the number of $\mathrm{Ti}$ atoms in cross sectional direction must be higher than those in vertical direction. 

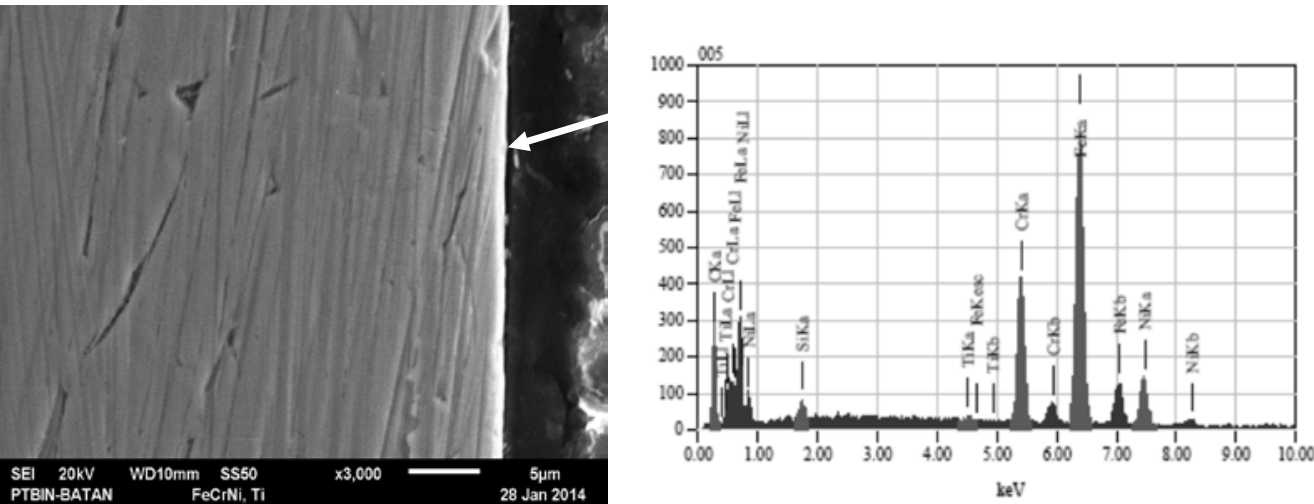

Figure 2: Cross-sectional SEM image of FeCrNi super alloy after Ti implantation at dose $10.75 \times 10^{16}$ ion $/ \mathrm{cm}^{2}$ and coresponding EDX spectrum at position indicated by arrow.

XRD measurement confirmed the presence of Ti containing phase on the sample surface having FCC crystall structure after implantation at dose $10.75 \times 10^{16} \mathrm{ion} / \mathrm{cm}^{2}$ as can be seen in Fig. 3 right. From peak analysis it might be the titanium oxide of the type $\mathrm{TiO}_{2}$.
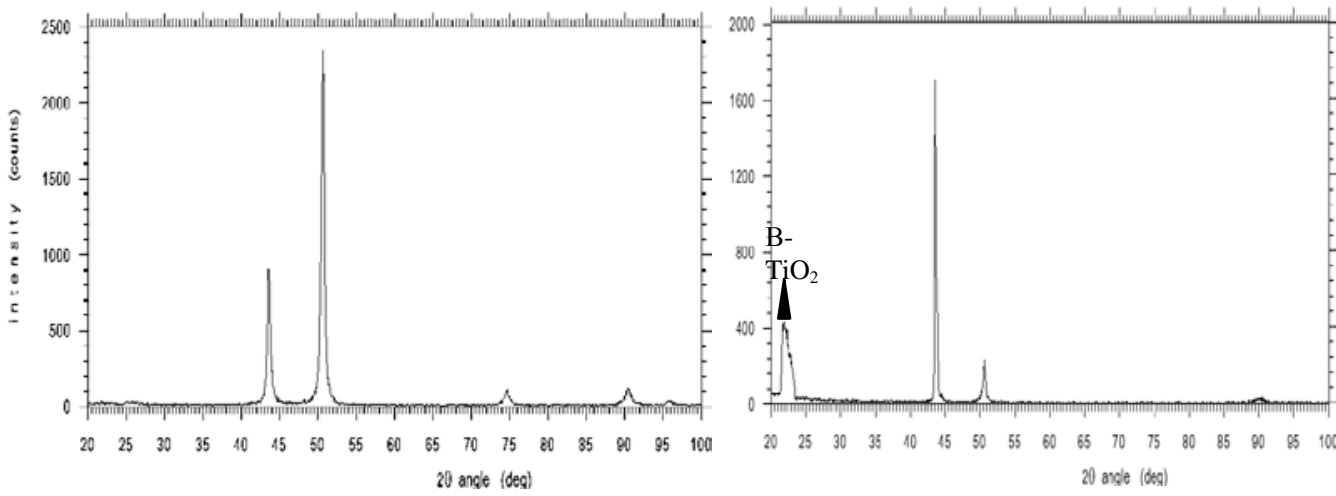

Figure 3: XRD diffraction spectrum of FeCrNi alloy before (left) and after Ti implantation (right).

The results of the wet corrosion are presented in figure 4 . The corrosion rate significantly decreases as early as implantation conducted from the initial rate at 0,17 millimeter per-year (mpy) down to 0,01 mpy and remains nearly constant at all doses. This is almost 17 times of magnitude. It can be concluded that in contrast to the surface hardness, at the applied acceleration energy of $100 \mathrm{keV} \mathrm{Ti}$ implantation obviously increases the corrosion behaviour of the alloy surface for all dose applied. The sample surface become exceptionally resistent against corrosion attack. The independency of the corrosion rate on the applied dosis implies that the corrosion resistancy is pure surface effect. This stand in agreement to the SEM result as presented above. This effect is seem to be directly related with the presence of Ti rich layer on the surface. Ti build chemical barrier to the corrosion attact or mechanical effect, the impingement during implantation cause the surface damage increases the number of defects which modify its surface property as already discussed in earlier study of Feng et al. [7]. 


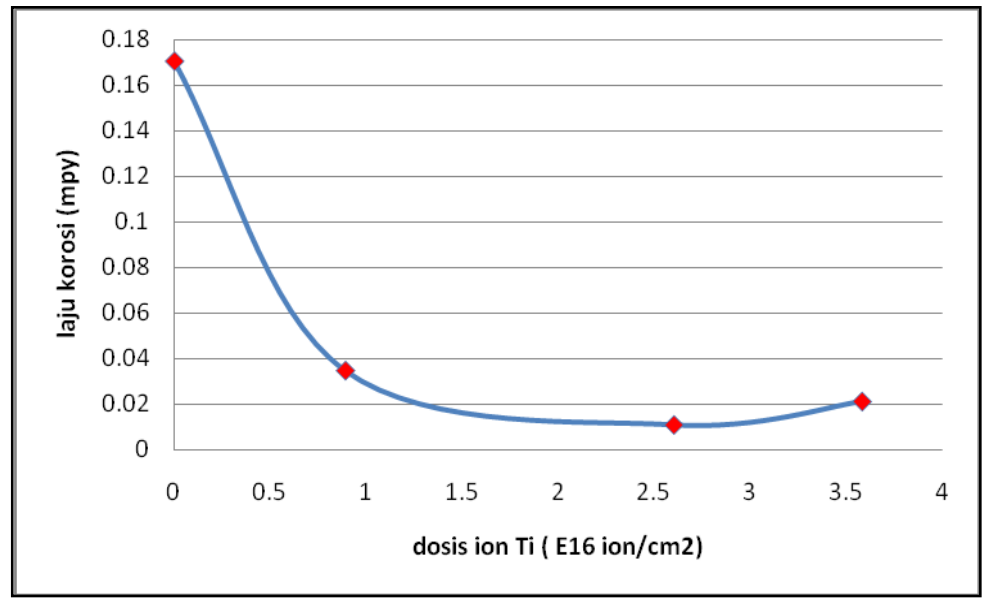

Figure 4: Corrosion rate as a function of ion dosis

\section{Conclusion}

From the observation, there is no increasing of the surface hardness of high $\mathrm{Cr}$ and $\mathrm{Ni}$ content FeCrNi alloy after Ti ion implatation at lower dosis up to $3.58 \times 10^{16}$ ion $/ \mathrm{cm}^{2}$. The hardness increase when the dose applied was higher than $10.75 \times 10^{16} \mathrm{ion} / \mathrm{cm}^{2}$. However, the corrosion resistance in acidic solution increased significantly and is not dependent to applied ion dosis. The depth profile of implanted Ti atoms could not measured in this study because of the detection limit of the used EDX technique. But in wide range the result stand in aggreement with earlier studies.

\section{Acknowledgment}

The authors gratefully thanks to Center of Science and Technology of Advance Material for financial support, thanks to Sumaryo, Rohmad Salam and Agus Sujatna for technical support during this research.

\section{References}

[1] A. L. Stepanov, Rev. Adv. Mater. Sci. 30 (2012) 150-165.

[2] A. A. Youssef ${ }^{a}$, P. Budzynski ${ }^{b}$, J. Filiks ${ }^{c}$, A. P. Kobzev ${ }^{d}$, J. Sielanko ${ }^{c}$, Vacuum, Vol. 77, Issue 1 (2004) P. 37-45.

[3] N. Kumar, S. Kataria, S. Dash, S. K. Srivastava, C. R. Das, P. Chandramohan, A. K. Tyagi, K. G. M. Nair, Baldev Raj, Wear, Volumes 274-275, 27 January 2012, Pages 60-67.

[4] D. P. Hickey, Diss, University of Florida (2007).

[5] A. Yu. Didyk, R. Wiśniewski, K .Kitowski, V. Kulikauskas, T. Wilczynska, A. A. Shiryaev, Ya. V. Zubavichus, Depth concentrations of deuterium ions implanted into some pure metals and alloys.

[6] P. J. Evans, J. Hyvarinen, M. Samandi, Surface and Coating Technology 71 (1995) 151-158. 
[7] K. Feng, X. Cai, Z. Li, P. K. Chu, Mat. Letters 68 (2012) 450-452.

[8] G. Jatisukamto, V. Malau, M. N. Ilman, P. T. Iswanto, J. Ilmiah Teknik Mesin CakraM, Vol. 5, No.1 (2011) 14-19.

[9] Effendi, N., Urania, 16(2), 2010.

[10] A. Sujatno, R. Salam, B. Bandriyana, A. Dimyati, Studi Scanning Electron Microscopy (SEM) untuk Karakterisasi Proses Oxidasi Paduan Zirkonium, Seminar Nasional X, SDM Teknologi Nuklir (2014).

[11] M. Vigen Karimi, S. K. Sinha, D. C. Kothari, A. K. Khanna, A. K. Tyagi, Surface and Coatings Techology 158-159 (2004) 609-614. 